\title{
Structural and computational analysis of intermolecular interactions in a new 2-thiouracil polymorph
}

\section{Ivana Fabijanić, Dubravka Matković-Čalogović, Viktor Pilepić and Krešimir Sanković}

Acta Cryst. (2017). C73, 1078-1086

\section{H IUCr Journals CRYSTALLOGRAPHY JOURNALS ONLINE}

Copyright (C) International Union of Crystallography

Author(s) of this paper may load this reprint on their own web site or institutional repository provided that this cover page is retained. Republication of this article or its storage in electronic databases other than as specified above is not permitted without prior permission in writing from the IUCr.

For further information see http://journals.iucr.org/services/authorrights.html 


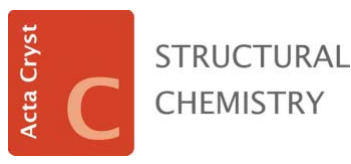

ISSN 2053-2296

Received 27 July 2017

Accepted 23 October 2017

Edited by M. Kubicki, Adam Mickiewicz University, Poland

Keywords: 2-thiouracil polymorph; X-ray diffraction; DNA model system; computational chemistry; crystal structure; QTAIM and $\mathrm{NCI}$ plot analysis.

CCDC reference: 1535305

Supporting information: this article has supporting information at journals.iucr.org/c

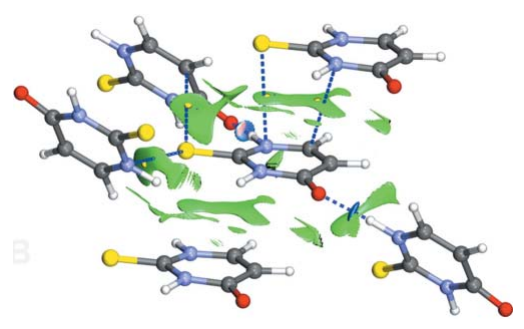

C 2017 International Union of Crystallography

\section{Structural and computational analysis of inter- molecular interactions in a new 2-thiouracil polymorph}

\author{
Ivana Fabijanić, ${ }^{a}$ Dubravka Matković-Čalogović, ${ }^{b} *$ Viktor Pilepićc ${ }^{c *}$ and Krešimir \\ Sankovićd
}

\footnotetext{
a Division of Materials Physics, Laboratory for Optics and Optical Thin Films, Ruđer Bošković Institute, Bijenička cesta 54 Zagreb 10000, Croatia, 'b Department of Chemistry, Faculty of Science, University of Zagreb, Horvatovac 102a, Zagreb 10000, Croatia, 'Department of Physical Chemistry, Faculty of Pharmacy and Biochemistry, University of Zagreb, A. Kovačića 1, Zagreb 10000, Croatia, and d Department of Biophysics, Faculty of Pharmacy and Biochemistry, University of Zagreb, A. Kovačića 1, Zagreb 10000, Croatia. *Correspondence e-mail: dubravka@chem.pmf.hr, vpilepic@pharma.hr
}

The crystallization and characterization of a new polymorph of 2-thiouracil by single-crystal X-ray diffraction, Hirshfeld surface analysis and periodic density functional theory (DFT) calculations are described. The previously published polymorph $(A)$ crystallizes in the triclinic space group $P \overline{1}$, while that described herein $(B)$ crystallizes in the monoclinic space group $P 2_{1} / c$. Periodic DFT calculations showed that the energies of polymorphs $A$ and $B$, compared to the gas-phase geometry, were -108.8 and $-29.4 \mathrm{~kJ} \mathrm{~mol}^{-1}$, respectively. The two polymorphs have different intermolecular contacts that were analyzed and are discussed in detail. Significant differences in the molecular structure were found only in the bond lengths and angles involving heteroatoms that are involved in hydrogen bonds. Decomposition of the Hirshfeld fingerprint plots revealed that $\mathrm{O} \cdots \mathrm{H}$ and $\mathrm{S} \cdots \mathrm{H}$ contacts cover over $50 \%$ of the noncovalent contacts in both of the polymorphs; however, they are quite different in strength. Hydrogen bonds of the $\mathrm{N}-\mathrm{H} \cdots \mathrm{O}$ and $\mathrm{N}-\mathrm{H} \cdots \mathrm{S}$ types were found in polymorph $A$, whereas in polymorph $B$, only those of the $\mathrm{N}-\mathrm{H} \cdots \mathrm{O}$ type are present, resulting in a different packing in the unit cell. QTAIM (quantum theory of atoms in molecules) computational analysis showed that the interaction energies for these weak-to-medium strength hydrogen bonds with a noncovalent or mixed interaction character were estimated to fall within the ranges 5.4-10.2 and 4.9$9.2 \mathrm{~kJ} \mathrm{~mol}^{-1}$ for polymorphs $A$ and $B$, respectively. Also, the NCI (noncovalent interaction) plots revealed weak stacking interactions. The interaction energies for these interactions were in the ranges $3.5-4.1$ and $3.1-5.5 \mathrm{~kJ} \mathrm{~mol}^{-1}$ for polymorphs $A$ and $B$, respectively, as shown by QTAIM analysis.

\section{Introduction}

Single crystals of DNA bases can be used as model systems of the natural DNA molecule, for example, for studying longrange charge migration along the DNA molecule. The longlasting problem of DNA conductance (Livshits et al., 2014) has been the subject of discussion, since some experiments demonstrated that DNA can carry electric current (Fanget et al., 2014), while others showed no such conductance in DNA (Porath et al., 2004). The transfer of electrons/holes over considerable distances in single crystals of purine or pyrimidine bases was researched in our previous experiments using the EPR spectroscopic properties of sulfur-centred radicals. We hypothesized that charge transfer occurs either by the overlapping of $\pi$-orbitals (base stacking) or by the ions potentially present in the environment of the DNA bases (Kabiljo et al., 1990; Herak et al., 1994, 1997, 1999, 2000, 2001; 
Sanković et al., 1996, 2003). The ring stacking of a DNA base in a single crystal resembles the base stacking in natural DNA (Jeffrey \& Kinoshita, 1963; McClure \& Craven, 1973; Mandel, 1977; Padmaja et al., 1987; Grainger \& Bailey, 1981; Bugg \& Thewalt, 1970; Iball \& Wilson, 1965; Matković-Čalogović \& Sanković, 1999, 2002; Prugovečki et al., 2005; Sanković et al., 2005).

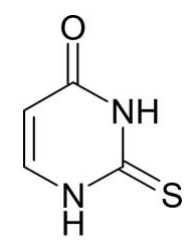

2-Thiouracil

Polymorph $A$ of 2-thiouracil [Cambridge Structural Database (CSD; Groom et al., 2016) refcode TURCIL] was first mentioned in the dissertation thesis of Tsernoglou (1967); however, only the unit cell, but no coordinates, was deposited in the CSD. The room-temperature crystal structure (TURCIL01) was published by Tiekink (1989). The lowtemperature structure at $90 \mathrm{~K}$ (TURCIL02), including the topological features of the charge densities, was determined by Munshi \& Guru Row (2006), who quantitatively described all of the chemical bonds by topological analysis based on Bader's quantum theory of atoms in molecules (QTAIM) (Bader, 1990; Popelier, 2000). Jarzembska et al. (2012) analyzed the crystal structure at $100 \mathrm{~K}$ (TURCIL03), as well as the crystal packings of 2-thiouracil and some selected uracil derivatives. Recently, the structure of TURCIL03 was refined by Hirshfeld atom refinement (Woinska et al., 2016).

In this article, we present the crystal structure of a new polymorph of 2-thiouracil (denoted polymorph $B$ ). Thanks to the above-mentioned published structure of the $A$ polymorph, we now have an opportunity to examine the differences in the intermolecular bonding and base stacking in two different crystal structures of the same nucleic base. The intermolecular bonding networks for 2-thiouracil polymorphs $A$ and $B$ were explored in this study with periodic density functional theory (DFT) calculations. The wavefunctions and electron densities obtained for the experimentally determined atomic coordinates and unit-cell parameters in the crystal polymorphs were analyzed by noncovalent interaction (NCI) plots, i.e. the pictorial representations of intermolecular bonding interactions (Johnson et al., 2010; Otero-de-la-Roza et al., 2012; Saleh et al., 2012). Also, the nature of the individual intermolecular interactions was examined in detail using QTAIM analysis (Bader, 1990; Popelier, 2000).

\section{Experimental}

\subsection{Crystallization of polymorph $B$}

All of the chemicals used for the synthesis were of analytical grade, purchased from Merck (2-thiouracil) and Kemika $(\mathrm{HCl})$, and used without further purification. The new polymorph of 2-thiouracil was prepared by dissolving 2-thiouracil $(1 \mathrm{mmol}, 128 \mathrm{mg})$ in $\mathrm{HCl}\left(20.0 \mathrm{ml}, 1 \mathrm{~mol} \mathrm{dm}^{-3}\right)$ in a capped flask at $333 \mathrm{~K}$ in a water bath for $1 \mathrm{~h}$ with continuous stirring. It was then left to evaporate slowly at about $300 \mathrm{~K}$ in a beaker covered with a watch glass to reduce the rate of evaporation. Colourless crystals were obtained after a period of approximately one month. The crystals were stable in air and of good quality for single-crystal X-ray diffraction analysis. A series of crystallization experiments were carried out to establish the conditions needed for crystallization of polymorph $B$. Crystallization trials were monitored by powder X-ray diffraction (PXRD). The concentration of $\mathrm{HCl}$ in the crystallization solutions was varied from 0 to $6 \mathrm{~mol} \mathrm{dm}^{-3}$. 2-Thiouracil $(0.5 \mathrm{mmol}, 64 \mathrm{mg})$ was added to $\mathrm{HCl}(10 \mathrm{ml})$ (concentrations $0,0.2,0.4,0.6,0.8,1,1.5,3$ and $6 \mathrm{~mol} \mathrm{dm}{ }^{-3}$ ). The solubility of 2-thiouracil depends on the concentration of $\mathrm{HCl}$, so after heating with continuous stirring for about $15 \mathrm{~min}$ at $333 \mathrm{~K}$, all the solutions were filtered and the saturated solutions were left to evaporate at room temperature. In all the tested concentrations of $\mathrm{HCl}$, crystals of polymorph $A$ appeared first. The crystals were filtered off after $2 \mathrm{~d}$ and analyzed by PXRD, and then filtered off again when the volume of the solutions had reduced to about $2 \mathrm{ml}$ in order to eliminate mixtures of polymorphs. The solutions were left to evaporate until only a very small amount of liquid was present and the crystals were again analyzed by PXRD. Only polymorph $A$ crystallized when lower concentrations of $\mathrm{HCl}\left(0\right.$ to $\left.0.4 \mathrm{~mol} \mathrm{dm}^{-3}\right)$ were the starting concentrations, while a mixture of polymorphs $A$ and $B$ was obtained from the last filtrate from the initial concentration of $0.6 \mathrm{~mol} \mathrm{dm}^{-3} \mathrm{HCl}$. Polymorph $B$ was obtained from solutions with initial concentrations of 0.8 $6 \mathrm{~mol} \mathrm{dm}{ }^{-3} \mathrm{HCl}$. Crystals of both polymorphs are colourless and some experience was needed to distinguish them under a microscope (pictures of the crystals of both polymorphs are given in the supporting information). The concentration of $\mathrm{HCl}$ in the solutions after evaporation to about $0.5 \mathrm{ml}$ was found to be $6.4 \mathrm{~mol} \mathrm{dm}^{-3}$ in both analyzed cases (from starting concentrations of $\mathrm{HCl}$ of 0.6 and $0.8 \mathrm{~mol} \mathrm{dm}^{-3}$ ). Good-quality crystals of polymorph $B$ were obtained from these two starting $\mathrm{HCl}$ concentrations. Interestingly, crystals obtained from the $6 \mathrm{~mol} \mathrm{dm}{ }^{-3} \mathrm{HCl}$ concentrations were of poor quality (dendritic and bristly).

\subsection{Single crystal $X$-ray structure determination}

The crystallographic data are summarized in Table 1. Due to the short $\mathrm{N} 1-\mathrm{H} 1$ bond length $(0.79 \AA)$ involving the $\mathrm{H}$ atom found in the difference Fourier map, it was decided to have a uniform treatment of all $\mathrm{H}$ atoms and they were placed in calculated positions and refined using the riding model, with $U_{\text {iso }}(\mathrm{H})$ values set at $1.2 U_{\text {eq }}$ of their respective bonding partners.

\subsection{Powder X-ray diffraction analysis (PXRD)}

PXRD data were collected on a PANalytical X'Change powder diffractometer in the Bragg-Brentano geometry using $\mathrm{Cu} K \alpha$ radiation $(\lambda=1.54056 \AA)$ at room temperature. Samples were contained on a Si sample holder. Diffraction patterns were collected in the $2 \theta$ range $5-30^{\circ}$ in continuous 
Table 1

Experimental details.

Crystal data

Chemical formula

$M_{\text {r }}$

Crystal system, space group

Temperature (K)

$a, b, c(\AA)$

$\beta\left(^{\circ}\right.$ )

$V\left(\AA^{3}\right)$

Z

Radiation type

$\mu\left(\mathrm{mm}^{-1}\right)$

Crystal size (mm)

$\mathrm{C}_{4} \mathrm{H}_{4} \mathrm{~N}_{2} \mathrm{OS}$

128.15

Monoclinic, $P 2_{1} / c$

298

4.1043 (2), 11.0458 (4), 12.0465 (4)

$93.740(3)$

544.97 (4)

4

Mo $K \alpha$

0.48

$0.42 \times 0.16 \times 0.12$

Data collection

Diffractometer

Absorption correction

$T_{\min }, T_{\max }$

No. of measured, independent and observed $[I>2 \sigma(I)]$ reflections

$R_{\text {in }}$

$(\sin \theta / \lambda)_{\max }\left(\AA^{-1}\right)$

Agilent Xcalibur Sapphire3

Multi-scan (CrysAlis PRO;

Agilent, 2014)

$0.985,1.000$

$2639,1367,1169$

0.016

0.671

Refinement

$R\left[F^{2}>2 \sigma\left(F^{2}\right)\right], w R\left(F^{2}\right), S$

$0.030,0.081,1.05$

1367

73

No. of parameters

$\mathrm{H}$-atom treatment

$\Delta \rho_{\max }, \Delta \rho_{\min }\left(\mathrm{e} \AA^{-3}\right)$

H-atom parameters constrained $0.24,-0.24$

Computer programs: CrysAlis PRO (Agilent, 2014), SHELXS97 (Sheldrick, 2008), SHELXL2014 (Sheldrick, 2015), PLATON (Spek, 2009), Mercury (Macrae at al., 2008) and WinGX (Farrugia, 2012).

scan mode. PXRD data were collected and visualized using the $X^{\prime}$ Pert HighScore Plus package (PANalytical, 2003).

\subsection{Hirshfeld surface analysis}

Based on the crystal structures of polymorphs $A$ and $B$, the Hirshfeld surface was generated by the program Crystal-

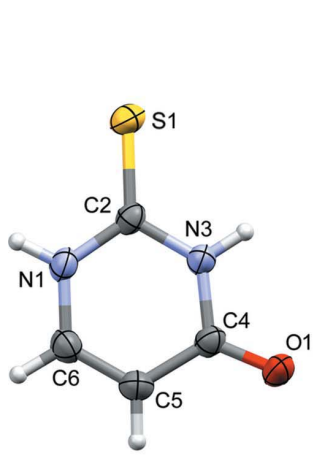

(a)

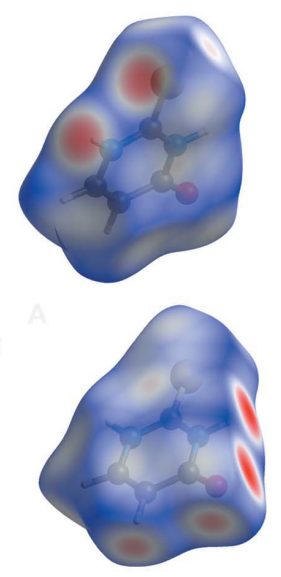

(b)

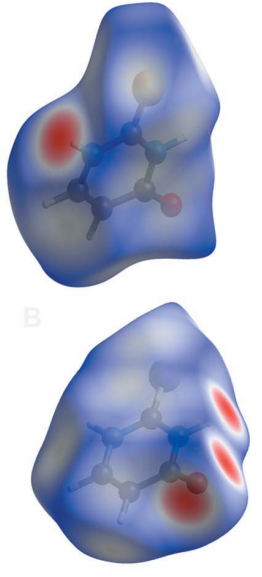

(c)
Figure 1

(a) The molecular structure of 2-thiouracil (polymorph $B$ ), showing the atom-labelling scheme. Displacement ellipsoids are drawn at the $50 \%$ probability level and $\mathrm{H}$ atoms are drawn as spheres of arbitrary radii. Graphical presentations of the Hirshfeld surfaces (with mapped $d_{\text {norm }}$ property) of (b) polymorph $A$ and (c) polymorph $B$. The two top figures present the molecule tilted such that atoms N1 and S1 are toward the viewer, while the two bottom figures present the molecule tilted such that atoms $\mathrm{C} 5$ and $\mathrm{O} 1$ are toward the viewer.
Explorer (Wolff et al., 2012). In order to determine noncovalent interactions in the crystal structures, the normalized contact distances, i.e. $d_{\text {norm }}$ (McKinnon et al., 2007), were mapped onto the Hirshfeld surfaces. Contacts were analyzed in relation to the van der Waals radii, i.e. those shorter than the sum of the van der Waals radii ( $d_{\text {norm }}$ negative; red colour), those close to the sum of the van der Waals radii ( $d_{\text {norm }}$ equal to zero; white colour) and those longer than the sum of the van der Waals radii ( $d_{\text {norm }}$ positive; blue colour) (Fig. 1$)$. Additionally, Hirshfeld surface fingerprint plots were generated. They represent 2D (two-dimensional) histograms of the $d_{\mathrm{i}}$ and $d_{\mathrm{e}}$ distances; $d_{\mathrm{i}}$ corresponds to the distance from the surface to the nearest atom in the molecule itself, whereas $d_{\mathrm{e}}$ corresponds to the distance from the surface to the nearest atom of a neighbouring molecule. The contribution of the contact pairs to the global surface is presented by a colour gradient in the plots going from blue to red (smaller to greater contribution).

\subsection{Computational methods}

The initial atomic coordinates and unit-cell parameters for the periodic DFT calculations of polymorphs $A$ and $B$ were taken from the CSD (refcode TURCIL03; Jarzembska et al., 2012) and our X-ray diffraction experiment, respectively. The calculations started with a geometry optimization of all of the $\mathrm{H}$ atoms within the entire unit cell for both polymorphs. The coordinates of all atoms heavier than hydrogen were fixed and all of the $\mathrm{H}$ atoms were geometry optimized under periodic conditions using the mixed Gaussian and plane wave $C P 2 \mathrm{~K}$ software package (CP2K, 2004; VandeVondele et al., 2005). The periodic H-atom geometry optimization of the unit cell was performed with the BLYP functional (Becke, 1988; Lee et al., 1988), GTH pseudopotential (Goedecker et al., 1996; Hartwigsen et al., 1998), optimized TZVP-MOLOPT-GTH basis sets (VandeVondele \& Hutter, 2007), 400 Ry cutoff for the plane wave grid and the Grimme D3 dispersion correction (Grimme et al., 2010). Single-point calculation was performed with the same level of theory, with a 1400 Ry cutoff for the plane wave grid and the Grimme D3 dispersion correction in order to obtain the wavefunctions and electron density of the periodic cells for polymorphs $A$ and $B$. The pictorial representation of the NCI plots and QTAIM topological analysis from the periodic electron densities of polymorphs $A$ and $B$ were made using the $V M D$ software package (Humphrey et al., 1996). The NCI plots were obtained by plotting the $\operatorname{sign}\left(\lambda_{2}\right) \rho(r)$ values with two cutoff values, $\rho_{\text {cut }}^{+}$and $\rho_{\text {cut }}^{-}$, colour mapped onto the reduced density gradient (RDG) isosurface, $s(r)$. [Fuller information on the significance of $\lambda_{2}$, the second density Hessian eigenvalue, is given by Otero-de-la-Roza et al. (2012).] The density cutoff values were used for setting the colour scale of the obtained domains, red-green-blue for $\rho_{\text {cut }}^{+}$ (red) and $\rho_{\text {cut }}^{-}$(blue), respectively (Otero-de-la-Roza et al., 2014).

\section{Results and discussion}

\subsection{Crystallization}

Up to now, crystals of 2-thiouracil have been prepared from several different solvents, namely by evaporation of an 
Table 2

Bond lengths $(\AA)$ and angles $\left(^{\circ}\right)$ in the crystal structures of 2-thiouracil polymorphs $A$ and $B$.

$A^{\mathrm{LT}}$ are data at $100 \mathrm{~K}$ (Jarzembska et al., 2012) and were obtained after transferable aspherical atom model (TAAM) refinement, $A^{\mathrm{RT}}$ are room-temperature data (Tiekink, 1989) obtained after the standard independent atom model (IAM) refinement and $B$ data obtained after IAM refinement.

\begin{tabular}{|c|c|c|c|c|c|c|c|}
\hline \multicolumn{4}{|c|}{ Bond lengths } & \multicolumn{4}{|c|}{ Bond angles } \\
\hline & $A^{\mathrm{LT}}$ & $A^{\mathrm{RT}}$ & $B$ & & $A^{\mathrm{LT}}$ & $A^{\mathrm{RT}}$ & $B$ \\
\hline $\mathrm{C} 2-\mathrm{N} 1$ & $1.3521(4)$ & $1.338(4)$ & $1.3524(16)$ & $\mathrm{N} 1-\mathrm{C} 2-\mathrm{N} 3$ & $116.29(3)$ & $116.0(3)$ & $114.86(11)$ \\
\hline $\mathrm{C} 2-\mathrm{S} 1$ & $1.6839(4)$ & $1.683(3)$ & $1.6670(12)$ & $\mathrm{N} 3-\mathrm{C} 2-\mathrm{S} 1$ & $121.78(2)$ & $121.8(2)$ & $122.06(10)$ \\
\hline $\mathrm{C} 4-\mathrm{O} 1$ & $1.2318(4)$ & $1.227(4)$ & $1.2427(15)$ & $\mathrm{O} 1-\mathrm{C} 4-\mathrm{N} 3$ & $119.44(4)$ & $119.2(3)$ & $119.06(12)$ \\
\hline $\mathrm{C} 4-\mathrm{N} 3$ & 1.3951 (4) & $1.389(4)$ & $1.3836(16)$ & $\mathrm{O} 1-\mathrm{C} 4-\mathrm{C} 5$ & $125.05(4)$ & $125.4(3)$ & $125.78(12)$ \\
\hline $\mathrm{C} 4-\mathrm{C} 5$ & $1.4443(5)$ & $1.432(5)$ & $1.4307(18)$ & $\mathrm{N} 3-\mathrm{C} 4-\mathrm{C} 5$ & $115.51(3)$ & $115.4(3)$ & 115.15 \\
\hline \multirow{2}{*}{$\mathrm{C} 6-\mathrm{N} 1$} & & & & $\mathrm{C} 2-\mathrm{N} 1-\mathrm{C} 6$ & $122.64(3)$ & $122.9(3)$ & $122.96(11)$ \\
\hline & & & & $\mathrm{C} 2-\mathrm{N} 3-\mathrm{C} 4$ & $125.32(3)$ & $125.2(3)$ & $126.26(11)$ \\
\hline
\end{tabular}

aqueous methanol solution (Tiekink, 1989), by evaporation of a water solution (Jarzembska et al., 2012) or from $N, N$-dimethylformamide (Munshi et al., 2006). In all the published cases, 2-thiouracil crystallized in the triclinic system, with space group $P \overline{1}$ (polymorph $A$ ). In contrast, we prepared crystals of 2-thiouracil from $0.6-6 \mathrm{~mol} \mathrm{dm}^{-3} \mathrm{HCl}$, which crystallized in the monoclinic crystal system, with space group $P 2_{1} / c$ (polymorph $B$; Fig. 1 ).

\subsection{Molecular structure}

The largest difference in the molecular structures of the two polymorphs is in the $\mathrm{C} 2-\mathrm{S} 1$ and $\mathrm{C} 4-\mathrm{O} 1$ bond lengths and the angles involving atom $\mathrm{C} 2$ (Table 2). The $\mathrm{C} 2-\mathrm{S} 1$ bond is shorter and $\mathrm{C} 4-\mathrm{O} 1$ longer in polymorph $B$ than in polymorph $A$. The $\mathrm{N} 1-\mathrm{C} 2-\mathrm{N} 3$ angle is smaller, whereas the $\mathrm{N} 1-\mathrm{C} 2-$ $\mathrm{S} 1$ and $\mathrm{N} 3-\mathrm{C} 2-\mathrm{S} 1$ angles are larger in polymorph $B$ than in polymorph $A$. These differences can be explained by their different involvement in hydrogen bonding, i.e. shorter hydrogen bonds involving the $\mathrm{S}$ atom in polymorph $A$, and a greater involvement of the $\mathrm{O}$ atom in the hydrogen bonding in polymorph $B$ (Fig. 1, see the Hirshfeld surfaces of the two polymorphs). The focus in this article is on the differences in the intermolecular contacts and the packing in the unit cell. These differences are also discussed using the Hirshfeld structure analysis and NCI and QTAIM descriptors.

Structures of several other thiouracil derivatives are known, namely 1-methyl-4-thiouracyl (Hawkinson, 1975), 5-methyl-2thiouracil (Matković-Čalogović et al., 2002), 4-thiouracil and 2,4-dithiouracil (Jarzembska et al., 2012), and 6-methyl-2thiouracil (Jarzembska et al., 2012, 2013; Parry \& Strachan, 1958); however, none have polymorphs that have been found so far.

\subsection{Crystal structure}

It was observed in thiouracil structures that hydrogen bonds of the $\mathrm{N}-\mathrm{H}$. . O or $\mathrm{N}-\mathrm{H}$...S type (or both) play a dominant role in the crystal packing (Jarzembska et al., 2012). Each of these hydrogen-bond types is involved in centrosymmetric dimer formation in polymorph $A$. The rings formed by dimerization can be described as $R_{2}^{2}(8)$ (Fig. 2). Both of these synthons are involved in polymorph $A$ in an alternating fashion forming chains. The $\mathrm{N} 1-\mathrm{H} 1$ group is a hydrogenbond donor in the $\mathrm{N} 1-\mathrm{H} 1 \cdots \mathrm{S} 1^{\mathrm{i}}$ dimer, whereas atom $\mathrm{N} 3$ is involved in the $\mathrm{N} 3-\mathrm{H} 3 \cdots \mathrm{O} 1^{\mathrm{ii}}$ dimer (see Table 3 for hydrogen-bond geometry and symmetry codes). Quite differently, in polymorph $B$, the $\mathrm{S}$ atoms are involved only in weak $\mathrm{C}-\mathrm{H}$. . S contacts, so the synthon involving dimers formed by $\mathrm{N}-\mathrm{H} \cdots \mathrm{S}$ hydrogen bonds is not present. This is not unusual since sulfur is less electronegative and more polarizable, thus resulting in more variations of the hydrogen bonds in which it

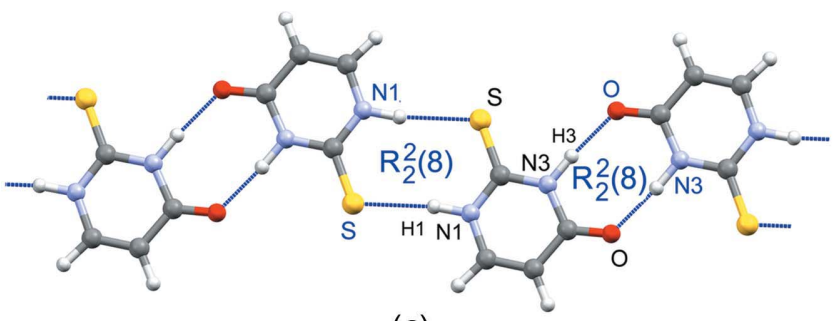

(a)

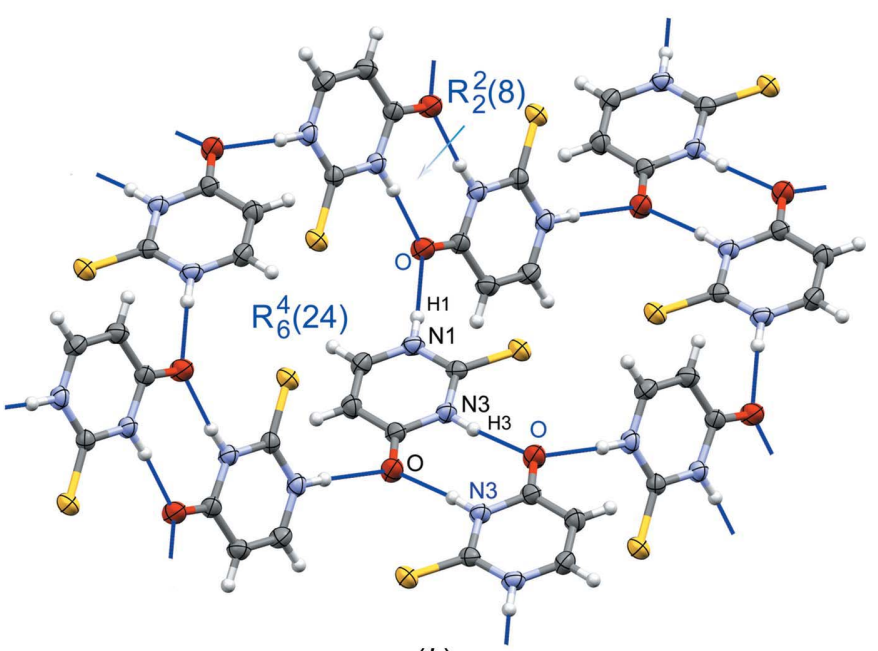

Figure 2

(b)

Hydrogen-bonding network (blue dotted lines) in the crystal structures of (a) polymorph $A$ and $(b)$ polymorph $B$ (the $\mathrm{C}-\mathrm{H} \cdots \mathrm{O}$ hydrogen bond in polymorph $A$ is not shown). The donor and acceptor atoms in the central molecules are labelled in black and those of neighbouring molecules are labelled in blue. 
is involved. Only the synthon formed by two centrosymmetrically related $\mathrm{N} 3-\mathrm{H} 3 \cdots \mathrm{O} 1^{\mathrm{vi}}$ hydrogen bonds, that connect two molecules into a dimer, is also found in polymorph $B$ (Fig. 2). In polymorph $B$, each $\mathrm{O}$ atom is a hydrogen-bond acceptor of two strong hydrogen bonds, whereas in polymorph $A$, it accepts only one strong and one weak (C5-H5 $\cdots \mathrm{O} 1^{\mathrm{iii}}$ ) hydrogen bond. In both polymorphs, the more acidic $\mathrm{H}$ atom on $\mathrm{N} 3$ is involved in the dimeric $\mathrm{N}-\mathrm{H} \cdots \mathrm{O}$ hydrogen-bond motif. In polymorph $B$, four dimers are interconnected through $\mathrm{N} 1-\mathrm{H} 1 \cdots \mathrm{O} 1^{\mathrm{v}}$ hydrogen bonds, forming large centrosymmetric rings defined as $R_{6}^{4}(24)$ by graph-set notation (Bernstein et al., 1995). In this way, endless puckered layers are formed, parallel to (100) (Fig. 3).

The difference between the two polymorphs is also seen in the further connection of the above-mentioned units by weak intermolecular hydrogen bonds, and in the crystal packing (Fig. 3). In polymorph $A$, the layers are flat and are formed by secondary $\mathrm{C}-\mathrm{H} \cdots \mathrm{O}$ hydrogen bonds interconnecting the chains. In this way, centrosymmetric $R_{6}^{4}(20)$ rings can be defined. In polymorph $B$, the puckered layers are connected by $\mathrm{C}-\mathrm{H} \cdots \mathrm{S}$ contacts. Interactions involving $\mathrm{S}$ atoms in polymorph $B$ are very weak, only slightly shorter than the sum of the van der Waals radii (Table 3 ).

As we are interested in interlayer distances and stacking interactions, it was of interest to study the differences between the two polymorphs. In polymorph $A$, the parallel layers are related to each other via the unit-cell translation along the $a$ axis [4.2859 (7) $\AA$ ] (Tiekink, 1989); however, the perpendicular distance between successive layers is $3.48 \AA$ (Tiekink, 1989). Short distances between individual atoms in these layers are $\mathrm{C} 5 \cdots \mathrm{C} 2(x+1, y, z)$ of $3.33189(5) \AA$ and $\mathrm{C} 5 \cdots \mathrm{O}(-x+1,-y,-z+1)$ of $3.2170(4) \AA$ at $100 \mathrm{~K}$ (Jarzembska et al., 2012). In polymorph $B$, a $C g \cdots C g(x-1, y$, $z$ ) distance of 4.1043 (7) $\AA$ was found, with a slippage of $2.278 \AA$ ( $C g$ is the centroid of the pyrimidine ring). The distance between layers is 3.4144 (5) $\AA$, while the individual shortest contact is $\mathrm{C} 2 \cdots \mathrm{C} 6(x-1, y, z)$ of 3.4271 (18) $\AA$.

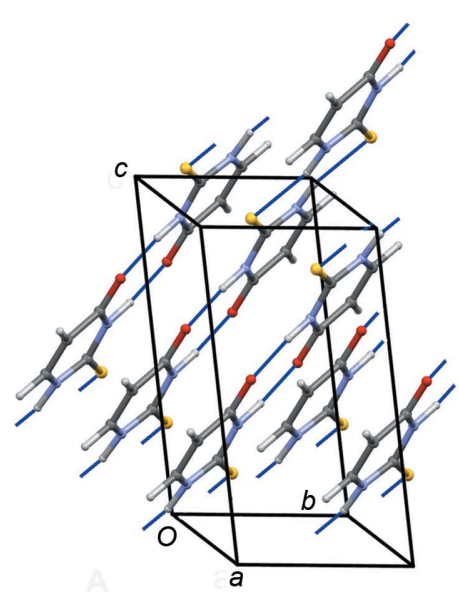

(a)

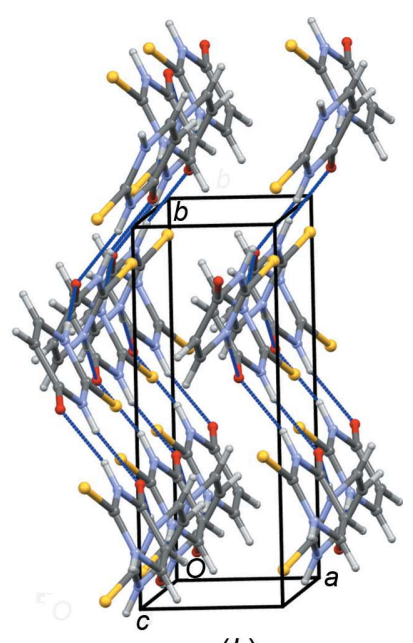

(b)
Figure 3

The packing of $(a)$ polymorph $A$ and $(b)$ polymorph $B$ in the unit cell. Hydrogen bonds are shown as thin blue lines.
Table 3

Hydrogen-bond geometry $\left(\AA,^{\circ}\right)$ for the $\mathrm{N}-\mathrm{H} \cdots \mathrm{O}, \mathrm{N}-\mathrm{H} \cdots \mathrm{S}$ and $\mathrm{C}-$ $\mathrm{H} \cdots \mathrm{O}$ interactions for polymorphs $A$ and $B$.

The first row data for the polymorph $A$ entries are at $100 \mathrm{~K}$ (Jarzembska et al., 2012; data obtained after TAAM refinement), while the second row presents room-temperature data (Tiekink, 1989). Contact geometry is given for C$\mathrm{H} \cdots \mathrm{S}$ interactions.

\begin{tabular}{|c|c|c|c|c|}
\hline & $D-\mathrm{H}$ & $\mathrm{H} \cdots A$ & $D \cdots A$ & $D-\mathrm{H} \cdots A$ \\
\hline \multicolumn{5}{|l|}{ Polymorph $A$} \\
\hline \multirow[t]{2}{*}{$\mathrm{N} 1-\mathrm{H} 1 \cdots \mathrm{S} 1^{\mathrm{i}}$} & 1.029 (1) & $2.292(2)$ & 3.2991 (3) & $165.7(2)$ \\
\hline & 0.90 & 2.44 & 3.315 (3) & 164 \\
\hline \multirow[t]{2}{*}{$\mathrm{N} 3-\mathrm{H} 3 \cdots \mathrm{O} 1^{\mathrm{ii}}$} & $1.029(1)$ & 1.795 (1) & $2.8202(4)$ & $173.6(2)$ \\
\hline & 0.90 & 1.94 & $2.835(4)$ & 175 \\
\hline \multirow[t]{2}{*}{$\mathrm{C} 5-\mathrm{H} 5 \cdots \mathrm{O} 1^{\mathrm{iii}}$} & $1.083(1)$ & $2.263(2)$ & 3.3377 (4) & $171.4(1)$ \\
\hline & 0.83 & 2.54 & $3.362(4)$ & 164 \\
\hline \multirow[t]{2}{*}{$\mathrm{C} 6-\mathrm{H} 6 \cdots \mathrm{S} 1^{\mathrm{iv}}$} & $1.082(1)$ & $2.771(4)$ & $3.6363(3)$ & $136.8(3)$ \\
\hline & 0.94 & 2.91 & $3.663(3)$ & 138 \\
\hline
\end{tabular}

Polymorph $B$

\begin{tabular}{|c|c|c|c|}
\hline$\overline{\mathrm{N} 1-\mathrm{H} 1 \cdots \mathrm{O} 1^{\mathrm{v}}}$ & 0.86 & 1.99 & $2.8443(14)$ \\
\hline $\mathrm{N} 3-\mathrm{H} 3 \cdots \mathrm{O} 1^{\mathrm{vi}}$ & 0.86 & 2.06 & $2.9057(15)$ \\
\hline $\mathrm{C} 5-\mathrm{H} 5 \cdots \mathrm{S} 1^{\mathrm{vii}}$ & 0.86 & $2.97^{b}$ & 3.9031 (14) \\
\hline C6-H6 $\cdots \mathrm{S} 1^{\text {viii }}$ & 0.86 & $2.88^{a}$ & $3.7780(14)$ \\
\hline
\end{tabular}

Symmetry codes: (i) $-x,-y,-z$; (ii) $-x+1,-y+1,-z+1$; (iii) $-x+2,-y,-z+1$; (iv) $x+1, y-1, z$; (v) $x,-y+\frac{1}{2}, z+\frac{1}{2}$; (vi) $-x,-y+1,-z$; (vii) $x+1,-y+\frac{1}{2}, z-\frac{1}{2}$; (viii) $-x$, $y-\frac{1}{2},-z+\frac{1}{2}$. Notes: $(a)$ the value is shorter than the sum of the van der Waals radii by only $0.12 \AA ;(b)$ the value is shorter than the sum of the van der Waals radii by only $0.03 \AA$ A. Contact radii are those given in Bondi (1964).

\subsection{Hirshfeld surface analysis}

Noncovalent interactions in the crystal structures of the two polymorphs were further investigated by Hirshfeld surface analysis, providing more insight into the quality and quantity of these interactions. The graphical presentation in Fig. 1 clearly shows the differences in the intermolecular contacts. The red spots at the $\mathrm{N}-\mathrm{H}$ groups are common to both polymorphs and indicate the hydrogen-bond donors. Atom $\mathrm{C} 5$ is a hydrogen-bond donor only in polymorph $A$. The other difference involves the $\mathrm{S}$ atom, which is an acceptor of a hydrogen bond in polymorph $A$, whereas in polymorph $B$, the contact is of the van der Waals type (only slightly shorter). The white regions on the Hirshfeld surface (Fig. 1) indicate interactions of the van der Waals type. The decomposition of the fingerprint plots (Fig. 4) reveals that $\mathrm{O} \cdots \mathrm{H}$ and $\mathrm{S} \cdots \mathrm{H}$ contacts cover over $50 \%$ of the noncovalent contacts in both polymorphs $(51.9 \%$ in polymorph $A$ and $55.3 \%$ in polymorph $B)$. The difference in the lengths of the $\mathrm{S} \cdot \mathrm{H}$ interactions in the two polymorphs can be seen from the difference in the spikes that show these contacts. The other most represented contacts are those of the $\mathrm{H} \cdots \mathrm{H}$ and $\mathrm{C} \cdot \cdots \mathrm{H}$ types. Contacts of the C..S type account for 3.4 and $5.1 \%$, while those of the C. C type account for 3.8 and $3.1 \%$ in polymorphs $A$ and $B$, respectively (stacking interactions).

\subsection{Computational analysis}

The intermolecular interactions in the crystal structure of 2-thiouracil polymorph $A$ have been quantitatively described by Munshi \& Guru Row (2006) using QTAIM topological analysis on experimental and theoretically calculated densities, as well as by Jarzembska et al. (2012) using DFT energy- 

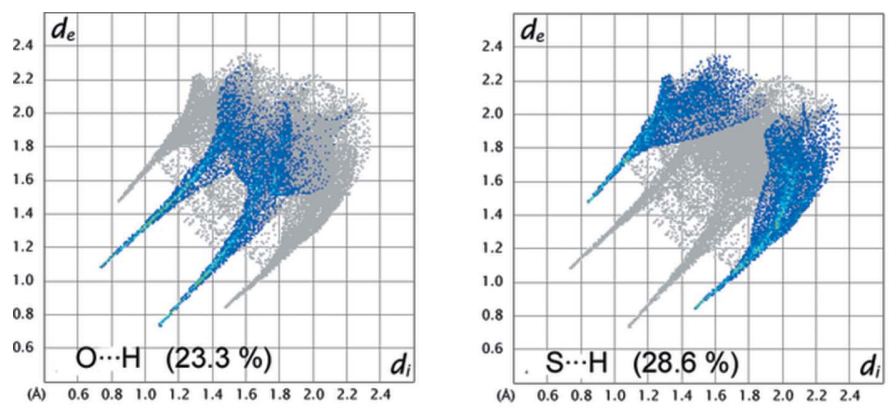

(a)
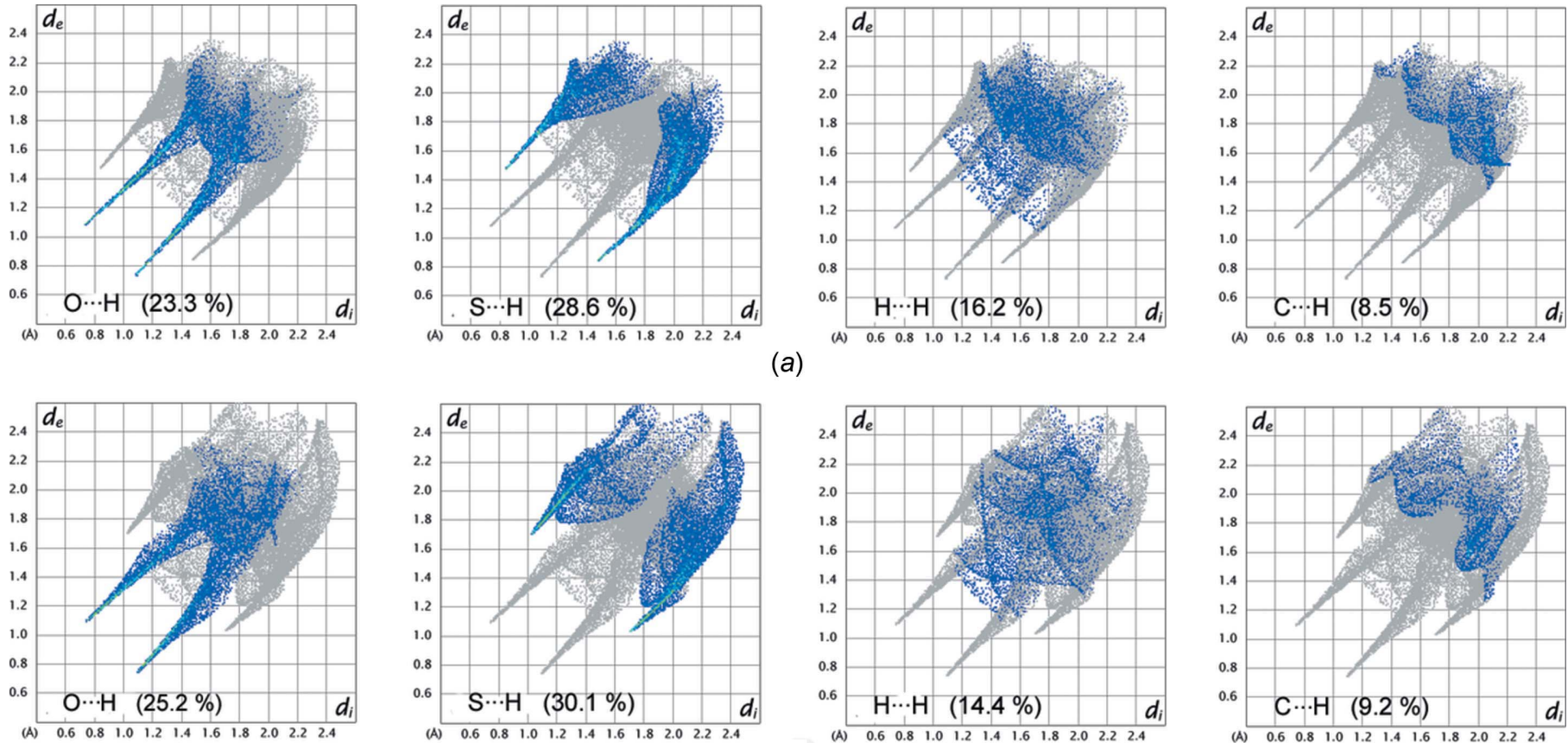

(b)

Figure 4

Hirshfeld fingerprint plots with decomposition of the dominant types of intermolecular contacts in $(a)$ polymorph $A$ and $(b)$ polymorph $B$.

and geometry-related properties. In this article, for comparison between the $A$ and $B$ polymorphs, we performed the periodic DFT computational analysis at the same level of theory. Taking into account the applied level of theory, the energies of polymorphs $A$ and $B$ compared to the gas-phase geometry-optimized structure were $-108.8 \mathrm{~kJ} \mathrm{~mol}^{-1}$ and $-29.4 \mathrm{~kJ} \mathrm{~mol}^{-1}$, respectively. The 2-thiouracil molecules in polymorph $B$ are arranged in zigzag positioned planes at an angle of about $114^{\circ}$ which enabled a different set of intermolecular interactions in comparison to the almost planar molecular arrangement in polymorph $A$. The intermolecular interactions responsible for the bonding attractions of 2-thiouracil molecules in polymorphs $A$ and $B$ were also explored with NCI and QTAIM descriptors. The noncovalent interaction (NCI) plots, developed by Johnson et al. (2010) and based on electron density and its derivative analysis, enable a visualization of the domains involved in either attractive or repulsive intermolecular interactions. The colourcoded red-green-blue domains of the NCI plots are interpreted as repulsive nonbonding, weak attractive and strong attractive interactions between the molecules in solids, respectively (Johnson et al., 2010; Otero-de-la-Roza et al., 2012; Saleh et al., 2012). NCI plots have been applied successfully in research with respect to hydrogen bonds, electrostatic, stacking and van der Waals interactions, molecular aggregations and crystal packing (Johnson et al., 2010; Otero-de-la-Roza et al., 2012). The NCI plots obtained from the periodic cell electron density for representative cluster units of polymorphs $A$ and $B$ are shown in Figs. 5 and 6 , respectively. Attractive domains represented with green-blue ellipsoids that can be attributed to $\mathrm{N}-\mathrm{H} \cdots \mathrm{O}, \mathrm{C}-\mathrm{H} \cdots \mathrm{O}$ and $\mathrm{N}-\mathrm{H} \cdots \mathrm{S}$ hydrogen bonds and $\mathrm{C}-\mathrm{H} \cdots \mathrm{S}$ contacts (Table 3 ) between a single 2-thiouracil molecule and its neighbours were found in both polymorphs. The nature of these intermolecular interactions was further characterized by a topological analysis of electron density within Bader's QTAIM analysis (Bader, 1990; Popelier, 2000). Within the framework of QTAIM, bond path $(3,-1)$ critical point $(\mathrm{BCP})$ properties are used for the analysis and classification of intermolecular

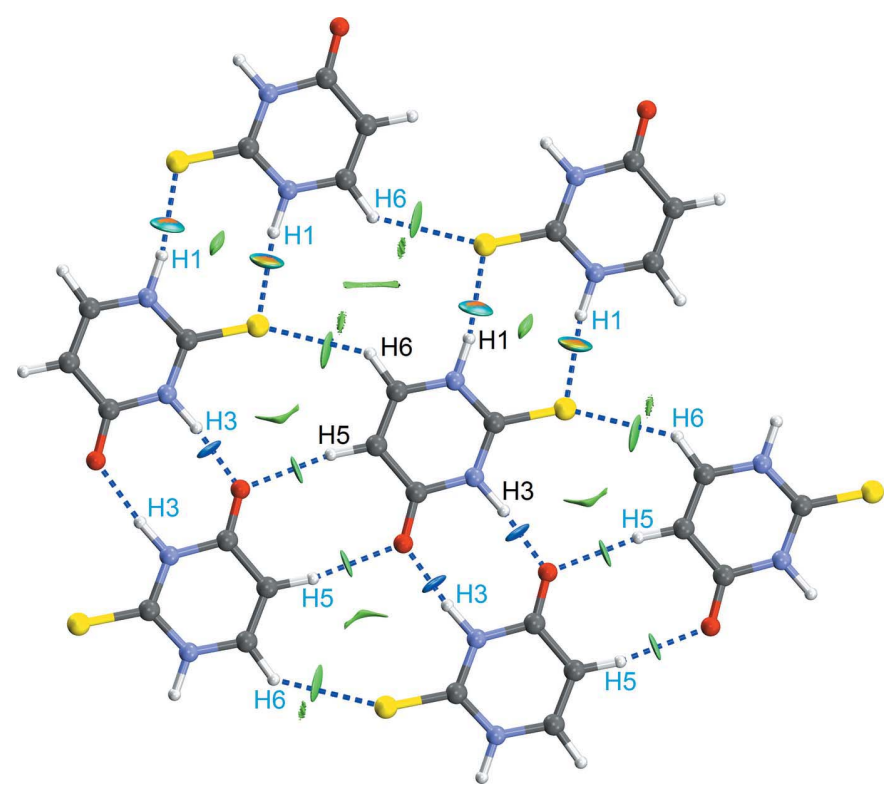

Figure 5

Selected noncovalent interaction (NCI) domains in the crystal structure of polymorph $A$. The reduced gradient isosurfaces at $s=0.5$ a.u. are coloured on a red-green-blue colour scale according to the $\operatorname{sign}\left(\lambda_{2}\right) \rho$ values ranging from -0.04 to 0.04 a.u., indicating repulsive nonbonding, weak attractive and strong attractive interactions, respectively. 
Table 4

QTAIM descriptors $^{a}$ of the selected bond path $(3,-1)$ critical points $(\mathrm{BCP})$ for intermolecular interactions in the crystal structures of polymorphs $A^{b}$ and $B^{c}$.

\begin{tabular}{|c|c|c|c|c|c|c|c|c|}
\hline $\mathrm{BCP}$ & & $\rho(r)$ & $\nabla^{2} \rho(r)$ & $G(r)$ & $V(r)$ & $H(r)$ & $|V(r)| / G(r)$ & Symmetry code \\
\hline$A 1$ & $\mathrm{H} 1 \cdots \mathrm{S} 1$ & 0.0256 & 0.0493 & 0.0064 & -0.0005 & 0.0059 & 0.0781 & $-x,-y,-z$ \\
\hline$A 3$ & $\mathrm{H} 5 \cdots \mathrm{O} 1$ & 0.0130 & 0.0476 & 0.0021 & 0.0078 & 0.0098 & 3.7143 & $-x+2,-y,-z+1$ \\
\hline$A 4$ & $\mathrm{H} 6 \cdots \mathrm{S} 1$ & 0.0090 & 0.0254 & 0.0011 & 0.0041 & 0.0052 & 3.7273 & $x+1, y-1, z$ \\
\hline$A 5$ & $\mathrm{~N} 1 \cdots \mathrm{S} 1$ & 0.0055 & 0.0164 & 0.0005 & 0.0031 & 0.0036 & 6.2000 & $x+1, y, z$ \\
\hline$A 6$ & N3 $\cdots$ S1 & 0.0060 & 0.0159 & 0.0006 & 0.0028 & 0.0034 & 4.6667 & $x+1, y, z$ \\
\hline \multicolumn{9}{|c|}{ Polymorph $B$} \\
\hline$B 1$ & $\mathrm{H} 1 \cdots \mathrm{O} 1$ & 0.0352 & 0.1055 & 0.0109 & 0.0047 & 0.0155 & 0.3133 & $x,-y+\frac{1}{2}, z+\frac{1}{2}$ \\
\hline$B 2$ & $\mathrm{H} 3 \cdots \mathrm{O} 1$ & 0.0302 & 0.0952 & 0.0084 & 0.0070 & 0.0154 & 0.8333 & $-x,-y,-z+1$ \\
\hline$B 3$ & $\mathrm{H} 5 \cdots \mathrm{S} 1$ & 0.0080 & 0.0222 & 0.0009 & 0.0037 & 0.0046 & 4.1111 & $x+1,-y+\frac{1}{2}, z-\frac{1}{2}$ \\
\hline$B 4$ & 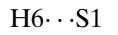 & 0.0097 & 0.0266 & 0.0013 & 0.0041 & 0.0054 & 3.1538 & $-x+1, y+\frac{1}{2},-z+\frac{3}{2}$ \\
\hline B5 & 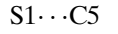 & 0.0055 & 0.0152 & 0.0005 & 0.0028 & 0.0033 & 5.6000 & $x,-y+\frac{1}{2}, z+\frac{1}{2}$ \\
\hline
\end{tabular}

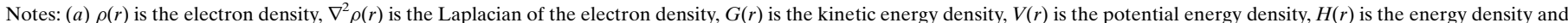

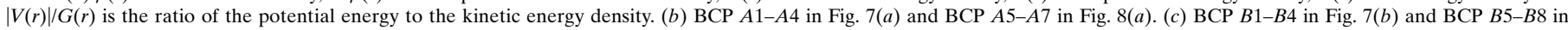
Fig. $8(b)$. All values are in atomic units (a.u.).

interactions. The electron density, $\rho(r)$, and the magnitude and sign of the energy density, $H(r)$, on the BCP are related to bonding strength. The value of the Laplacian of the electron density, $\nabla^{2} \rho(r)$, on the BCP indicates the degree of density concentration or depletion, and can be used to distinguish between shared-shell and closed-shell bonding interactions. The potential energy density, $V(r)$, value at BCP is correlated with hydrogen-bond energy (Grabowski, 2011). The potential energy density and the kinetic energy density ratio, $|V(r)| /$ $G(r)$, has a value larger than 2 for covalent bonds, a value between 1 and 2 for mixed character interactions, and a value lower than 1 for ionic, hydrogen-bond and van der Waals interactions (Popelier, 2000; Espinosa et al., 2002; Bianchi et al., 2000). The representation of the selected bond path (3,

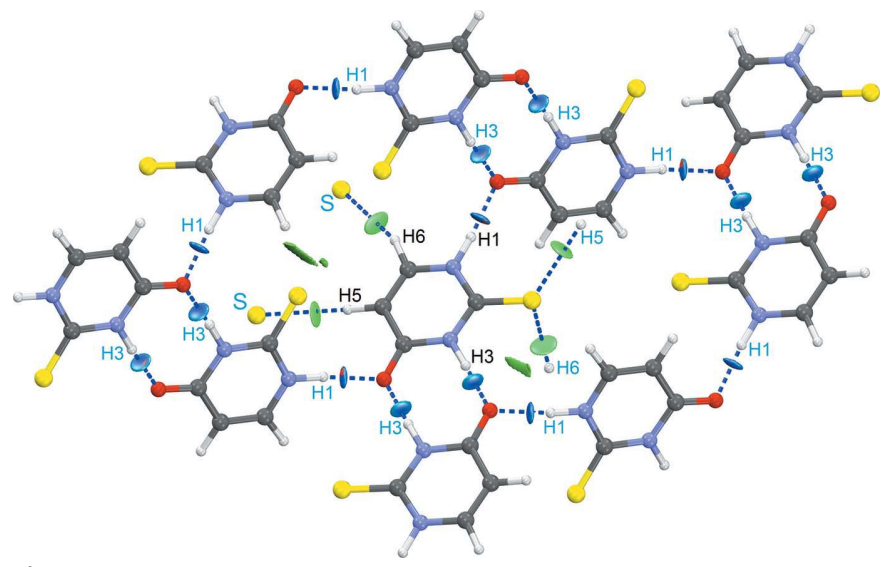

Figure 6

The selected noncovalent interaction (NCI) domains in the crystal structure of polymorph $B$. The reduced gradient isosurfaces at $s=0.5$ a.u. are coloured on a red-green-blue colour scale according to the $\operatorname{sign}\left(\lambda_{2}\right) \rho$ values ranging from -0.04 to 0.04 a.u., indicating repulsive nonbonding, weak attractive and strong attractive interactions, respectively.
-1) critical points and their properties, associated with the interaction of a single 2-thiouracil molecule with its surroundings in the crystal packing for the 2-thiouracil $A$ and $B$ polymorphs, is given in Fig. 7 and Table 4 . The NCI plots obtained for the $A$ and $B$ polymorphs resemble the BCPs. For polymorph $A$, the obtained BCPs $A 1-A 4$ and their properties were in accordance with the respective BCPs described by Munshi \& Guru Row (2006). BCP values $A 1-A 4$ were attributed to $\mathrm{N} 1-\mathrm{H} 1 \cdots \mathrm{S} 1^{\mathrm{i}}, \mathrm{N} 3-\mathrm{H} 3 \cdots \mathrm{O} 1^{\mathrm{ii}}$ and $\mathrm{C} 5-$ $\mathrm{H} 5 \cdots \mathrm{O} 1^{\mathrm{iii}}$ hydrogen bonds and $\mathrm{C} 6-\mathrm{H} 6 \cdots \mathrm{S} 1^{\mathrm{iv}}$ contacts, respectively, and the estimated interaction energies ranged from 5.4 to $10.2 \mathrm{~kJ} \mathrm{~mol}^{-1}$. For polymorph $B$, BCPs $B 1-B 4$ (Fig. $7 b$ and Table 4 ) were attributed to the $\mathrm{N} 1-\mathrm{H} 1 \cdots \mathrm{O} 1^{\mathrm{v}}$ and $\mathrm{N} 3-\mathrm{H} 3 \cdots \mathrm{O} 1^{\mathrm{vi}}$ hydrogen bonds and $\mathrm{C} 5-\mathrm{H} 5 \cdots \mathrm{S} 1^{\mathrm{vii}}$ and $\mathrm{C} 6-\mathrm{H} 6 \cdots \mathrm{S} 1^{\text {viii }}$ contacts, respectively. The estimated interaction energies ranged from 4.9 to $9.2 \mathrm{~kJ} \mathrm{~mol}^{-1}$, somewhat less than the estimated interaction energies obtained for polymorph $A$. The NCI plot for weak and stacking interactions and the corresponding selected bond path $(3,-1)$ critical points

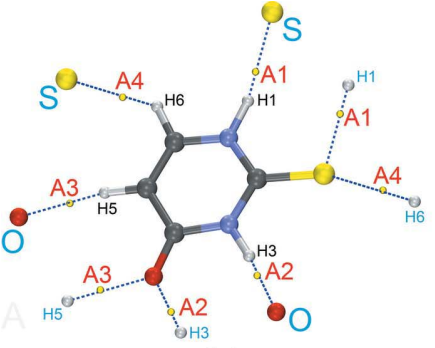

(a)

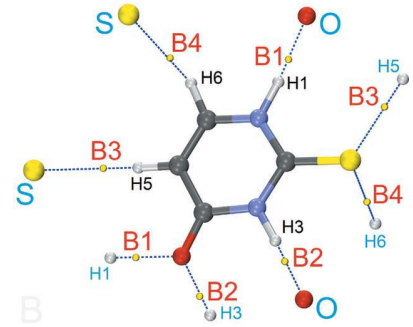

(b)
Figure 7

The selected bond path $(3,-1)$ critical points (BCPs), yellow dots identified with red labels, for intermolecular interactions in the crystal structures of $(a)$ polymorph $A$ and $(b)$ polymorph $B$. The QTAIM properties for BCPs $A 1-A 4$ and $B 1-B 4$ are given in Table 4 . 


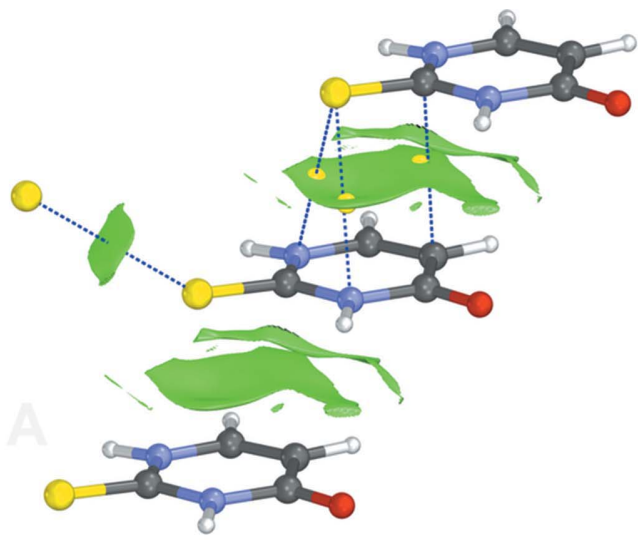

(a)

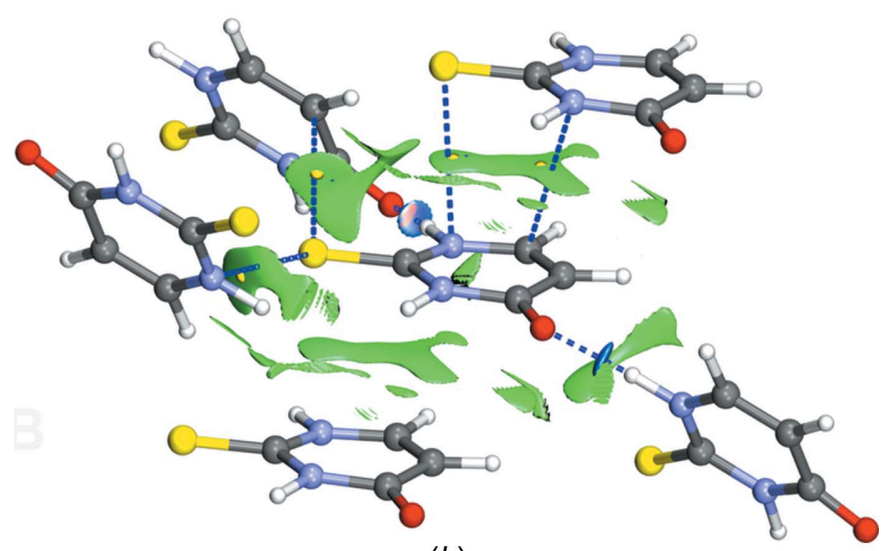

(b)

Figure 8

The selected noncovalent interaction (NCI) domains that represent weak and stacking intermolecular interactions in the crystal structures of polymorphs $A$ and $B$. The yellow spheres (not marked for clarity) represent the associated selected QTAIM bond path $(3,-1)$ critical points, viz. BCPs $A 5-A 7$ and $B 5-B 8$ (see Table 4).

and their properties are presented in Fig. 8 and Table 4. In polymorph $A$, the molecules are packed in shifted parallel planes and the NCI plot suggests that the weak stacking interactions involve contacts of N1, N3 and C5 atoms of one molecule with the $\mathrm{S} 1$ and $\mathrm{C} 2$ atoms of another molecule in the adjacent plane. The properties of the corresponding BCPs $A 5$, $A 6$ and $A 7$ suggested weak mixed-character bonding. The estimated interaction energy for these bonding interactions ranged from 3.5 to $4.1 \mathrm{~kJ} \mathrm{~mol}^{-1}$. The weak intermolecular S...S interaction reported by Munshi et al. (2006) was also represented in the NCI plot with the green ellipsoid between the $\mathrm{S}$ atoms separated by $3.634 \AA$ (Fig. $8 a$ ). The NCI plot obtained for polymorph $B$ (Fig. $8 b$ ) reveals weak bonding interactions of the S1 atom with atoms C5 and C6 of the neighbouring molecules at $\left(x,-y+\frac{1}{2}, z+\frac{1}{2}\right)$ and $\left(-x, y-\frac{1}{2}\right.$, $\left.-z+\frac{3}{2}\right)$, respectively. The corresponding BCPs $B 5$ and $B 6$ (Table 4) can be classified as weak mixed-character interactions. In 2-thiouracil polymorph $B$, molecules in parallel planes form weak stacking interactions through the N1 and C6 atoms of one molecule with the S1, C2 and N3 atoms of the molecule at $(x+1, y, z)$ in the adjacent plane (Fig. 8). The corresponding BCPs $B 7$ and $B 8$ could be classified as weak mixed-character attractions. The interaction energy for these weak bonding interactions were estimated at $3.1-5.5 \mathrm{~kJ} \mathrm{~mol}^{-1}$.

\section{Conclusion}

A new polymorph of 2-thiouracil (denoted polymorph $B$ ) was crystallized from an acidic aqueous medium and presented intermolecular contacts different from those in polymorph $A$. Significant differences in the molecular structures of the two polymorphs include the $\mathrm{C} 2-\mathrm{S} 1$ bond which is shorter, and the $\mathrm{C} 4-\mathrm{O} 1$ bond which is longer in polymorph $B$ than in polymorph $A$, resulting from differences in hydrogen bonding. Although the decomposition of the Hirshfeld fingerprint plots show that $\mathrm{O} \cdots \mathrm{H}$ and $\mathrm{S} \cdot \mathrm{H}$ contacts cover over $50 \%$ of the noncovalent contacts in both polymorphs, they are quite different in strength. In polymorph $A, \mathrm{~N} 1-\mathrm{H} 1 \cdots \mathrm{S} 1^{\mathrm{i}}$ and N3$\mathrm{H} 3 \cdots \mathrm{O} 1^{\mathrm{ii}}$ hydrogen bonds (Table 3 ) connect neighbouring molecules into dimers [both $R_{2}^{2}(8)$ according to graph-set notation]. In polymorph $B$, the $\mathrm{S}$ atom is not involved in strong hydrogen bonding (hence the shorter $\mathrm{C} 2-\mathrm{S} 1$ bond), and dimers of $R_{2}^{2}(8)$ type are formed only by $\mathrm{N} 3-\mathrm{H} 3 \cdots \mathrm{O} 1$ hydrogen bonds. Four such dimers are interconnected through $\mathrm{N} 1-\mathrm{H} 1 \cdots \mathrm{O} 1^{\mathrm{v}}$ hydrogen bonds (Table 3), forming large centrosymmetric rings defined as $R_{6}^{4}(24)$. The $\mathrm{O} 1$ atom is therefore an acceptor of two strong hydrogen bonds in polymorph $B$, influencing a lengthening of the $\mathrm{C}-\mathrm{O}$ bond. The QTAIM computational analysis showed that the interaction energies for these weak-to-medium strength hydrogen bonds with a noncovalent or mixed-interaction character can be estimated as 5.4-10.2 and 4.9-9.2 $\mathrm{kJ} \mathrm{mol}^{-1}$ for polymorphs $A$ and $B$, respectively. Weak stacking interactions are formed in both polymorphs, as revealed by the NCI plot analysis. The interaction energies for these weak stacking interactions are in the ranges $3.5-4.1$ and $3.1-5.5 \mathrm{~kJ} \mathrm{~mol}^{-1}$ for polymorphs $A$ and $B$, respectively. Taking into account the periodic DFT calculations at the applied level of theory, the energies of polymorphs $A$ and $B$ compared to the gas-phase geometryoptimized structure were -108.8 and $-29.4 \mathrm{~kJ} \mathrm{~mol}^{-1}$, respectively.

\section{Acknowledgements}

We are grateful to the University of Zagreb Computing Centre (SRCE) for computational time and resources.

\section{Funding information}

Funding for this research was provided by: University of Zagreb (grant Nos. BM092 and 20282206 - Synthesis and structural characterization of organic and complex compounds; structure of proteins).

\section{References}

Agilent (2014). CrysAlis PRO. Agilent Technologies Ltd, Yarnton, Oxfordshire, England.

Bader, R. F. W. (1990). In Atoms in Molecules: A Quantum Theory. Oxford University Press.

Becke, A. (1988). Phys. Rev. A, 38, 3098-3100. 
Bernstein, J., Davis, R. E., Shimoni, L. \& Chang, N.-L. (1995). Angew. Chem. Int. Ed. Engl. 34, 1555-1573.

Bianchi, R., Gervasio, G. \& Marabello, D. (2000). Inorg. Chem. 39, 2360-2366.

Bondi, A. (1964). J. Phys. Chem. 68, 441-451.

Bugg, C. E. \& Thewalt, U. (1970). J. Am. Chem. Soc. 92, 74417445.

CP2K (2004). Version 2.6.2. The CP2K developers group. https:// www.cp2k.org/.

Espinosa, E., Alkorta, I., Elguero, J. \& Molins, E. (2002). J. Chem. Phys. 117, 5529-5542.

Fanget, A., Traversi, F., Khlybov, S., Granjon, P., Magrez, A., Forró, L. \& Radenovic, A. (2014). Nano Lett. 14, 244-249.

Farrugia, L. J. (2012). J. Appl. Cryst. 45, 849-854.

Goedecker, S., Teter, M. \& Hutter, J. (1996). Phys. Rev. B, 54, $1703-$ 1710.

Grabowski, S. J. (2011). Chem. Rev. 111, 2597-2625.

Grainger, C. T. \& Bailey, D. (1981). Acta Cryst. B37, 1561-1564.

Grimme, S., Antony, J., Ehrlich, S. \& Krieg, H. (2010). J. Chem. Phys. 132, 154104.

Groom, C. R., Bruno, I. J., Lightfoot, M. P. \& Ward, S. C. (2016). Acta Cryst. B72, 171-179.

Hartwigsen, C., Goedecker, S. \& Hutter, J. (1998). Phys. Rev. B, 58, 3641-3662.

Hawkinson, S. W. (1975). Acta Cryst. B31, 2153-2156.

Herak, J. N., Sanković, K., Hole, E. O. \& Sagstuen, E. (2000). Phys. Chem. Chem. Phys. 2, 4971-4975.

Herak, J. N., Sanković, K., Hole, E. O. \& Sagstuen, E. (2001). Phys. Chem. Chem. Phys. 3, 4926-4931.

Herak, J. N., Sanković, K. \& Hüttermann, J. (1994). Int. J. Radiat. Biol. 66, 3-9.

Herak, J. N., Sanković, K., Krilov, D. \& Hüttermann, J. (1999). Radiat. Res. 151, 319-324.

Herak, J. N., Sanković, K., Krilov, D., Jakšić, M. \& Hüttermann, J. (1997). Radiat. Phys. Chem. 50, 141-148.

Humphrey, W., Dalke, A. \& Schulten, K. (1996). J. Mol. Graph. 14, 33-38.

Iball, J. \& Wilson, H. R. (1965). Proc. R. Soc. A, 288, 418-429.

Jarzembska, K. N., Kamiński, R., Wenger, E., Lecomte, C. \& Dominiak, P. M. (2013). J. Phys. Chem. C, 117, 7764-7775.

Jarzembska, K. N., Kubsik, M., Kaminski, R., Wozniak, K. \& Dominiak, P. M. (2012). Cryst. Growth Des. 12, 2508-2524.

Jeffrey, G. A. \& Kinoshita, Y. (1963). Acta Cryst. 16, 20-28.

Johnson, E. R., Keinan, S., Mori-Sanchez, P., Contreras-Garcia, J., Cohen, A. J. \& Yang, W. (2010). J. Am. Chem. Soc. 132, 64986506.

Kabiljo, Z., Sanković, K. \& Herak, J. N. (1990). Int. J. Radiat. Biol. 58, 439-447.

Lee, C., Yang, W. \& Parr, R. (1988). Phys. Rev. B, 37, 785-789.

Livshits, G. I., Stern, A., Rotem, D., Borovok, N., Eidelshtein, G., Migliore, A., Penzo, E., Wind, S. J., Di Felice, R., Skourtis, S. S.,
Cuevas, J. C., Gurevich, L., Kotlyar, A. B. \& Porath, D. (2014). Nat. Nano, 9, 1040-1046.

Macrae, C. F., Bruno, I. J., Chisholm, J. A., Edgington, P. R., McCabe, P., Pidcock, E., Rodriguez-Monge, L., Taylor, R., van de Streek, J. \& Wood, P. A. (2008). J. Appl. Cryst. 41, 466-470.

Mandel, N. S. (1977). Acta Cryst. B33, 1079-1082.

Matković-Čalogović, D., Besic, E. \& Sanković, K. (2002). Acta Cryst. C58, o568-0569.

Matković-Čalogović, D. \& Sanković, K. (1999). Acta Cryst. C55, 467469.

McClure, R. J. \& Craven, B. M. (1973). Acta Cryst. B29, 1234-1238.

McKinnon, J. J., Jayatilaka, D. \& Spackman, M. A. (2007). Chem. Commun. pp. 3814-3816.

Munshi, P. \& Guru Row, T. N. (2006). Acta Cryst. B62, 612-626.

Otero-de-la-Roza, A., Johnson, E. R. \& Contreras-García, J. (2012). Phys. Chem. Chem. Phys. 14, 12165-12172.

Otero-de-la-Roza, A., Johnson, E. R. \& Luaña, V. (2014). Comput. Phys. Commun. 185, 1007-1018.

Padmaja, N., Ramakumar, S. \& Viswamitra, M. A. (1987). Acta Cryst. C43, 2157-2160.

PANalytical (2003). X'Pert HighScore Plus. PANalytical BV, Almelo, The Netherlands.

Parry, G. S. \& Strachan, F. (1958). Acta Cryst. 11, 303-304.

Popelier, P. L. A. (2000). In Atoms in Molecules: An Introduction. Upper Saddle River: Pearson Education, Prentice Hall.

Porath, D., Cuniberti, G. \& Di Felice, R. (2004). Topics in Current Chemistry, Vol. 237, edited by G. Schuster, pp. 183-227. Heidelberg: Springer-Verlag. arXiv:cond-mat/0403640.

Prugovečki, B., Matković-Čalogović, D. \& Sanković, K. (2005). Acta Cryst. E61, o2706-02708.

Saleh, G., Gatti, C., Lo Presti, L. \& Contreras-García, J. (2012). Chem. Eur. J. 18, 15523-15536.

Sanković, K., Krilov, D., Pranjić-Petrović, T., Hüttermann, J. \& Herak, J. N. (1996). Int. J. Radiat. Biol. 70, 603-608.

Sanković, K., Malinen, E., Medunić, Z., Sagstuen, E. \& Herak, J. N. (2003). Phys. Chem. Chem. Phys. 5, 1665-1670.

Sanković, K., Prugovečki, B. \& Matković-Čalogović, D. (2005). Acta Cryst. E61, o3846-03848.

Sheldrick, G. M. (2008). Acta Cryst. A64, 112-122.

Sheldrick, G. M. (2015). Acta Cryst. C71, 3-8.

Spek, A. L. (2009). Acta Cryst. D65, 148-155.

Tiekink, E. R. T. (1989). Z. Kristallogr. 18, 779-782.

Tsernoglou, D. (1967). Diss. Abstr. B, 27, 2603-2604.

VandeVondele, J. \& Hutter, J. (2007). J. Chem. Phys. 127, 114105.

VandeVondele, J., Krack, M., Mohamed, F., Parrinello, M., Chassaing, T. \& Hutter, J. (2005). Comput. Phys. Commun. 167, 103-128.

Woinska, M., Grabowsky, S., Dominiak, P. M., Wozniak, K. \& Jayatilaka, D. (2016). Sci. Adv. 2, e1600192.

Wolff, S. K., Grimwood, D. J., McKinnon, J. J., Turner, D., Jayatilaka, M. J. \& Spackman, M. A. (2012). CrystalExplorer. Version 3.1. University of Western Australia. 


\section{supporting information}

Acta Cryst. (2017). C73, 1078-1086 [https://doi.org/10.1107/S205322961701542X]

\section{Structural and computational analysis of intermolecular interactions in a new 2- thiouracil polymorph}

\section{Ivana Fabijanić, Dubravka Matković-Čalogović, Viktor Pilepić and Krešimir Sanković}

Computing details

Data collection: CrysAlis PRO (Agilent, 2014); cell refinement: CrysAlis PRO (Agilent, 2014); data reduction: CrysAlis PRO (Agilent, 2014); program(s) used to solve structure: SHELXS97 (Sheldrick, 2008); program(s) used to refine structure: SHELXL2014 (Sheldrick, 2015); molecular graphics: Mercury (Macrae at al., 2008) and ORTEP-3 (Farrugia, 2012); software used to prepare material for publication: SHELXL2014 (Sheldrick, 2015).

2-Thiouracil

Crystal data

$\mathrm{C}_{4} \mathrm{H}_{4} \mathrm{~N}_{2} \mathrm{OS}$

$M_{r}=128.15$

Monoclinic, $P 2{ }_{1} / c$

$a=4.1043(2) \AA$

$b=11.0458(4) \AA$

$c=12.0465(4) \AA$

$\beta=93.740(3)^{\circ}$

$V=544.97(4) \AA^{3}$

$Z=4$

\section{Data collection}

Agilent Xcalibur Sapphire3

diffractometer

Radiation source: Enhance (Mo) X-ray Source

Detector resolution: 16.3426 pixels $\mathrm{mm}^{-1}$

$\omega$ scans

Absorption correction: multi-scan

(CrysAlis PRO; Agilent, 2014)

$T_{\min }=0.985, T_{\max }=1.000$

Refinement

Refinement on $F^{2}$

Least-squares matrix: full

$R\left[F^{2}>2 \sigma\left(F^{2}\right)\right]=0.030$

$w R\left(F^{2}\right)=0.081$

$S=1.05$

1367 reflections

73 parameters

0 restraints
$F(000)=264$

$D_{\mathrm{x}}=1.562 \mathrm{Mg} \mathrm{m}^{-3}$

Mo $K \alpha$ radiation, $\lambda=0.71073 \AA$

Cell parameters from 1185 reflections

$\theta=5.4-32.0^{\circ}$

$\mu=0.48 \mathrm{~mm}^{-1}$

$T=298 \mathrm{~K}$

Prismatic, colourless

$0.42 \times 0.16 \times 0.12 \mathrm{~mm}$

2639 measured reflections

1367 independent reflections

1169 reflections with $I>2 \sigma(I)$

$R_{\text {int }}=0.016$

$\theta_{\text {max }}=28.5^{\circ}, \theta_{\min }=5.0^{\circ}$

$h=-4 \rightarrow 5$

$k=-14 \rightarrow 13$

$l=-16 \rightarrow 12$

Hydrogen site location: inferred from neighbouring sites

$\mathrm{H}$-atom parameters constrained

$w=1 /\left[\sigma^{2}\left(F_{0}^{2}\right)+(0.0426 P)^{2}+0.0147 P\right]$

where $P=\left(F_{\mathrm{o}}^{2}+2 F_{\mathrm{c}}^{2}\right) / 3$

$(\Delta / \sigma)_{\max }=0.001$

$\Delta \rho_{\max }=0.24$ e $\AA^{-3}$

$\Delta \rho_{\min }=-0.24 \mathrm{e}^{-3}$ 


\section{Special details}

Geometry. All esds (except the esd in the dihedral angle between two 1.s. planes) are estimated using the full covariance matrix. The cell esds are taken into account individually in the estimation of esds in distances, angles and torsion angles; correlations between esds in cell parameters are only used when they are defined by crystal symmetry. An approximate (isotropic) treatment of cell esds is used for estimating esds involving l.s. planes.

Fractional atomic coordinates and isotropic or equivalent isotropic displacement parameters $\left(\AA^{2}\right)$

\begin{tabular}{lllll}
\hline & $x$ & $y$ & $z$ & $U_{\text {iso }} * U_{\text {eq }}$ \\
\hline C2 & $0.1455(3)$ & $0.15324(11)$ & $0.72131(10)$ & $0.0273(3)$ \\
C4 & $0.2895(3)$ & $0.15650(11)$ & $0.52702(10)$ & $0.0305(3)$ \\
C5 & $0.4587(3)$ & $0.26792(12)$ & $0.54972(11)$ & $0.0345(3)$ \\
H5 & 0.5709 & 0.3058 & 0.4948 & $0.041^{*}$ \\
C6 & $0.4529(3)$ & $0.31692(12)$ & $0.65168(10)$ & $0.0335(3)$ \\
H6 & 0.5600 & 0.3899 & 0.6664 & $0.040^{*}$ \\
N1 & $0.2937(3)$ & $0.26216(9)$ & $0.73413(8)$ & $0.0317(3)$ \\
H1 & 0.2873 & 0.2986 & 0.7971 & $0.038^{*}$ \\
N3 & $0.1503(3)$ & $0.10482(9)$ & $0.61723(8)$ & $0.0297(2)$ \\
H3 & 0.0578 & 0.0355 & 0.6067 & $0.036^{*}$ \\
O1 & $0.2582(3)$ & $0.10499(9)$ & $0.43524(8)$ & $0.0415(3)$ \\
S1 & $-0.03220(9)$ & $0.08280(3)$ & $0.82379(3)$ & $0.03738(14)$ \\
\end{tabular}

Atomic displacement parameters $\left(\AA^{2}\right)$

\begin{tabular}{lllllll}
\hline & $U^{11}$ & $U^{22}$ & $U^{33}$ & $U^{12}$ & $U^{13}$ & $U^{23}$ \\
\hline C2 & $0.0299(6)$ & $0.0275(6)$ & $0.0243(6)$ & $0.0053(5)$ & $0.0013(4)$ & $-0.0009(4)$ \\
C4 & $0.0403(7)$ & $0.0276(6)$ & $0.0236(6)$ & $0.0035(6)$ & $0.0031(5)$ & $0.0016(4)$ \\
C5 & $0.0416(8)$ & $0.0322(7)$ & $0.0301(6)$ & $-0.0035(6)$ & $0.0053(5)$ & $0.0031(5)$ \\
C6 & $0.0381(7)$ & $0.0261(6)$ & $0.0361(7)$ & $-0.0027(6)$ & $0.0005(5)$ & $-0.0005(5)$ \\
N1 & $0.0420(6)$ & $0.0279(5)$ & $0.0254(5)$ & $0.0018(5)$ & $0.0021(4)$ & $-0.0056(4)$ \\
N3 & $0.0401(6)$ & $0.0251(5)$ & $0.0240(5)$ & $-0.0014(5)$ & $0.0035(4)$ & $-0.0017(4)$ \\
O1 & $0.0680(7)$ & $0.0342(5)$ & $0.0226(5)$ & $-0.0058(5)$ & $0.0066(4)$ & $-0.0014(3)$ \\
S1 & $0.0456(2)$ & $0.0394(2)$ & $0.0283(2)$ & $-0.00086(15)$ & $0.01149(15)$ & $0.00031(12)$ \\
\hline
\end{tabular}

Geometric parameters $\left(\AA,{ }^{\circ}\right)$

\begin{tabular}{llll}
\hline $\mathrm{C} 2-\mathrm{N} 1$ & $1.3524(16)$ & $\mathrm{C} 5-\mathrm{C} 6$ & $1.3439(18)$ \\
$\mathrm{C} 2-\mathrm{N} 3$ & $1.3645(15)$ & $\mathrm{C} 5-\mathrm{H} 5$ & 0.9300 \\
$\mathrm{C} 2-\mathrm{S} 1$ & $1.6670(12)$ & $\mathrm{C} 6-\mathrm{N} 1$ & $1.3654(16)$ \\
$\mathrm{C} 4-\mathrm{O} 1$ & $1.2427(15)$ & $\mathrm{C} 6-\mathrm{H} 6$ & 0.9300 \\
$\mathrm{C} 4-\mathrm{N} 3$ & $1.3836(16)$ & $\mathrm{N} 1-\mathrm{H} 1$ & 0.8600 \\
$\mathrm{C} 4-\mathrm{C} 5$ & $1.4307(18)$ & $\mathrm{N} 3-\mathrm{H} 3$ & $121.62(12)$ \\
& & & 119.2 \\
$\mathrm{~N} 1-\mathrm{C} 2-\mathrm{N} 3$ & $114.86(11)$ & $\mathrm{C} 5-\mathrm{C} 6-\mathrm{N} 1$ & 119.2 \\
$\mathrm{~N} 1-\mathrm{C} 2-\mathrm{S} 1$ & $123.09(9)$ & $\mathrm{C} 5-\mathrm{C} 6-\mathrm{H} 6$ & $122.96(11)$ \\
$\mathrm{N} 3-\mathrm{C} 2-\mathrm{S} 1$ & $122.06(10)$ & $\mathrm{N} 1-\mathrm{C} 6-\mathrm{H} 6$ & 118.5 \\
$\mathrm{O} 1-\mathrm{C} 4-\mathrm{N} 3$ & $119.06(12)$ & $\mathrm{C} 2-\mathrm{N} 1-\mathrm{C} 6$ & \\
$\mathrm{O} 1-\mathrm{C} 4-\mathrm{C} 5$ & $125.78(12)$ & $\mathrm{C} 2-\mathrm{N} 1-\mathrm{H} 1$ &
\end{tabular}




\begin{tabular}{llll}
$\mathrm{N} 3-\mathrm{C} 4-\mathrm{C} 5$ & $115.15(11)$ & $\mathrm{C} 6-\mathrm{N} 1-\mathrm{H} 1$ & 118.5 \\
$\mathrm{C} 6-\mathrm{C} 5-\mathrm{C} 4$ & $118.93(12)$ & $\mathrm{C} 2-\mathrm{N} 3-\mathrm{C} 4$ & $126.26(11)$ \\
$\mathrm{C} 6-\mathrm{C} 5-\mathrm{H} 5$ & 120.5 & $\mathrm{C} 2-\mathrm{N} 3-\mathrm{H} 3$ & 116.9 \\
$\mathrm{C} 4-\mathrm{C} 5-\mathrm{H} 5$ & 120.5 & $\mathrm{C} 4-\mathrm{N} 3-\mathrm{H} 3$ & 116.9 \\
& & & \\
$\mathrm{O} 1-\mathrm{C} 4-\mathrm{C} 5-\mathrm{C} 6$ & $175.47(14)$ & $\mathrm{C} 5-\mathrm{C} 6-\mathrm{N} 1-\mathrm{C} 2$ & $3.3(2)$ \\
$\mathrm{N} 3-\mathrm{C} 4-\mathrm{C} 5-\mathrm{C} 6$ & $-4.11(18)$ & $\mathrm{N} 1-\mathrm{C} 2-\mathrm{N} 3-\mathrm{C} 4$ & $-0.03(19)$ \\
$\mathrm{C} 4-\mathrm{C} 5-\mathrm{C} 6-\mathrm{N} 1$ & $0.9(2)$ & $\mathrm{S} 1-\mathrm{C} 2-\mathrm{N} 3-\mathrm{C} 4$ & $179.64(10)$ \\
$\mathrm{N} 3-\mathrm{C} 2-\mathrm{N} 1-\mathrm{C} 6$ & $-3.66(18)$ & $\mathrm{O} 1-\mathrm{C} 4-\mathrm{N} 3-\mathrm{C} 2$ & $-175.79(11)$ \\
$\mathrm{S} 1-\mathrm{C} 2-\mathrm{N} 1-\mathrm{C} 6$ & $176.68(10)$ & $\mathrm{C} 5-\mathrm{C} 4-\mathrm{N} 3-\mathrm{C} 2$ & $3.8(2)$ \\
\hline
\end{tabular}

Hydrogen-bond geometry $\left(A,{ }^{\circ}\right)$

\begin{tabular}{lllll}
\hline$D-\mathrm{H} \cdots A$ & $D-\mathrm{H}$ & $\mathrm{H} \cdots A$ & $D \cdots A$ & $D-\mathrm{H} \cdots A$ \\
\hline $\mathrm{N} 1-\mathrm{H} 1 \cdots \mathrm{O} 1^{\mathrm{i}}$ & 0.86 & 1.99 & $2.8443(14)$ & 175 \\
$\mathrm{~N} 3-\mathrm{H} 3 \cdots \mathrm{O} 1^{\mathrm{ii}}$ & 0.86 & 2.06 & $2.9057(15)$ & 166 \\
$\mathrm{C} 5-\mathrm{H} 5 \cdots \mathrm{S} 1^{\mathrm{iii}}$ & 0.86 & 2.97 & $3.9031(14)$ & 176 \\
$\mathrm{C} 6-\mathrm{H} 6 \cdots \mathrm{S}^{\mathrm{iv}}$ & 0.86 & 2.88 & $3.7780(14)$ & 163
\end{tabular}

Symmetry codes: (i) $x,-y+1 / 2, z+1 / 2$; (ii) $-x,-y+1,-z$; (iii) $x+1,-y+1 / 2, z-1 / 2$; (iv) $-x, y-1 / 2,-z+1 / 2$. 